\title{
Apert Syndrome in the Era of Prenatal Diagnosis
}

\author{
${ }^{1}$ Florin Stamatian, ${ }^{2}$ Tunde Kovacs, ${ }^{3}$ Mariela Militaru, ${ }^{4}$ Gabriela Caracostea
}

\section{ABSTRACT}

Apert syndrome is a rare autosomal dominant disorder characterized by severe craniosynostosis, hypoplastic mediofacial structures and symmetric syndactyly. The syndactyly involves both cutaneous and osseous structures of the upper and lower limbs. Apart from skeletal anomalies, affected fetuses may often present central nervous system malformations and various visceral malformations (congenital heart defects, genitourinary anomalies, choanal stenosis, tracheal abnormalities, diaphragmatic hernia and omphalocele). Mental retardation is frequently encountered, as are a large variety of craniofacial and neurocognitive phenotypes. The incidence of Apert syndrome is approximately one in 65,000 newborns, representing $4.5 \%$ of all craniosynostosis cases. The first cases of Apert syndrome were diagnosed by ultrasound and fetoscopy in the third trimester of pregnancy. With the introduction of three-dimensional (3D) ultrasonography, identification of fetal changes characteristic of Apert syndrome is possible in the second trimester of pregnancy. Diagnosis confirmation requires fetal DNA analysis by fibroblast growth factor receptor 2 gene amplification (FGFR2) followed by sequencing and digestion with restriction enzymes. Recently, noninvasive prenatal diagnosis was reported using free fetal DNA analysis with cell-free fetal DNA (cffDNA) in maternal plasma by Polymerase Chain Reaction (PCR) assay and enzymatic digestion with restriction enzymes. As the syndrome has rarely been reported in Romania, we present the case of a fetus diagnosed with Apert syndrome in the second trimester of pregnancy. Early ultrasound detection of suggestive signs for this syndrome (craniosynostosis, syndactyly) was followed by confirmation of the diagnosis by prenatal fetal DNA analysis.

Keywords: Apert syndrome, Craniosynostosis, Syndactyly, Metopic suture.

How to cite this article: Stamatian F, Kovacs T, Militaru M, Caracostea G. Apert Syndrome in the Era of Prenatal Diagnosis. Donald School J Ultrasound Obstet Gynecol 2014;8(2):222-225.

Source of support: Nil

Conflict of interest: None

${ }^{1}$ Professor and Head, ${ }^{2}$ Teaching Assistant, ${ }^{3,4}$ Senior Physician

${ }^{1}$ Department of Obstetrics and Gynecology I, Director, Mother and Child Department; Member of the Romanian Academy of Medical Sciences; President of Romanian Society of Obstetrics and Gynecology, University of Medicine and Pharmacy 'luliu Hatieganu', Cluj-Napoca, Romania

${ }^{2,4}$ Department of Obstetrics and Gynecology I, University of Medicine and Pharmacy, 'Iuliu Hatieganu', Cluj-Napoca, Romania

${ }^{3}$ Department of Genetics, University of Medicine and Pharmacy 'Iuliu Hatieganu', Cluj-Napoca, Romania

Corresponding Author: Florin Stamatian, Professor and Head, First Gynecology Clinic, 3-5 Clinicilor St, Cluj-Napoca, Romania, Phone and Fax: +40-264450115, e-mail: florin_stamatian@yahoo.com

\section{CASE REPORT}

A 32-year-old, nulliparous, diabetic patient was referred to our Prenatal Diagnosis Centre at 22 weeks of gestation for fetal evaluation due to an anomaly of the upper limbs.

Biochemical and ultrasound screening performed in the first trimester indicated normal values. The husband was 41 years of age, and there was no consanguinity between the two partners.

For the ultrasound examination, a Voluson E8-Expert ultrasound machine was used. A male fetus was visualized with biometry corresponding to 22 weeks of gestation. The fetus had depressed nasal bridge, protuberant frontal bone, low-set ears, clover-leaf skull and polyhydramnios (Fig. 1A).

Three-dimensional ultrasound examination in maximum mode allowed the clear visualization of the wide metopic suture and the bilateral fusion of the coronal sutures (Fig. 1B).

Additionally, the fetus presented with complete syndactyly of fingers 2 to 5 (mitten-like hands) and complete cutaneous suture of the toes (Figs 2A and B).

The karyotype identified from amniotic fluid was 46, XY. FGFR2 gene analysis confirmed Apert syndrome by identifying the heterozygous genotype for the Pro253Arg variant. Analysis of the Ser252Trp and Pro253Arg variants of the FGFR2 gene were performed using Polymerase Chain Reaction-Restriction Fragment Length Polymorphism (PCR-RFLP) following Kiliç and Slaney protocol. ${ }^{1,2}$ Enzymatic digestion products were subjected to agarose gel electrophoresis and analyzed under ultraviolet light (Figs $3 \mathrm{~A}$ and $\mathrm{B})$.

After diagnosis confirmation, a multidisciplinary team informed the couple about the unfavorable fetal outcome, the risks of severe mental deficiencies, and the multiple surgical interventions required upon the skull and limbs. After counseling, the family chose a therapeutic termination of the pregnancy. Autopsy confirmed the ultrasound characteristics of Apert syndrome: mediofacial hypoplasia, craniosynostosis and syndactyly (Figs 4A and B).

\section{DISCUSSION}

Apert syndrome has characteristic cranial features, which are included in the group of craniosynostoses. Over 100 different types of craniosynostosis have been described, and more than half have a genetic cause. ${ }^{3}$ 

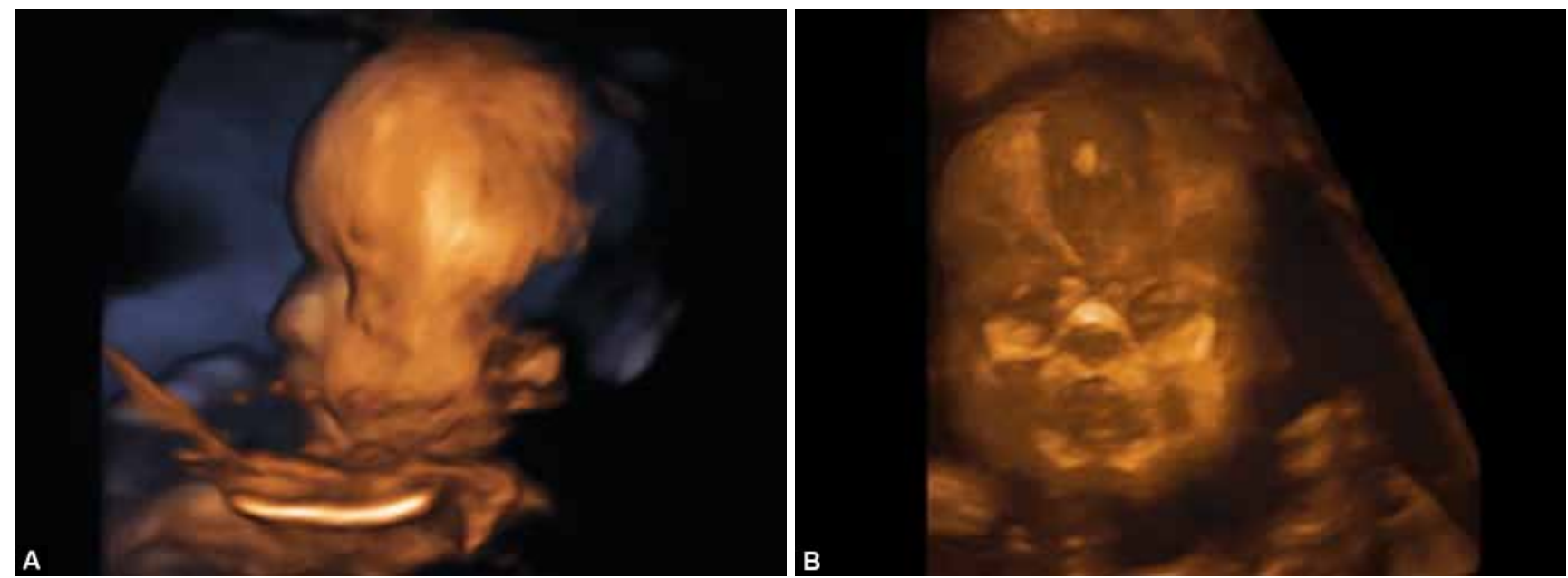

Figs $1 \mathrm{~A}$ and $\mathrm{B}:(\mathrm{A}) 3 \mathrm{D}$ ultrasound-depressed nasal bridge, protuberant frontal bone and $(\mathrm{B})$ the metopic suture
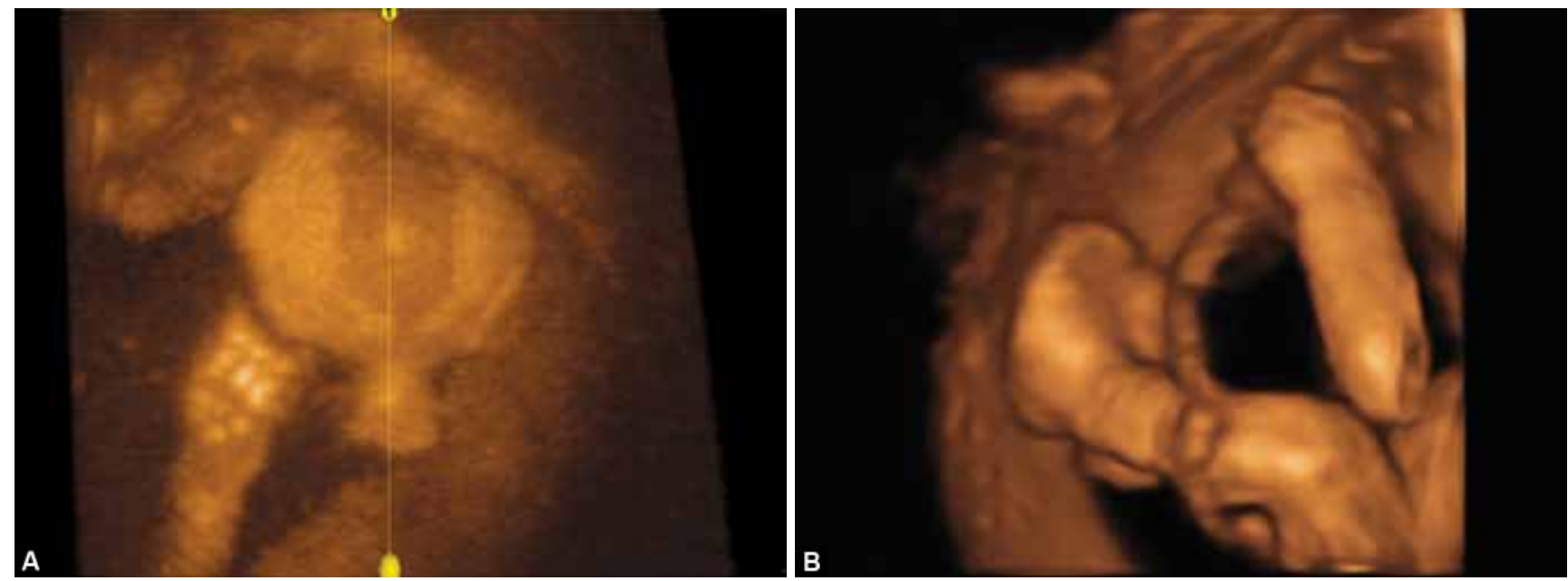

Figs 2A and B: (A) Metopic suture and mitten-like hands and $(B)$ suture of the toes

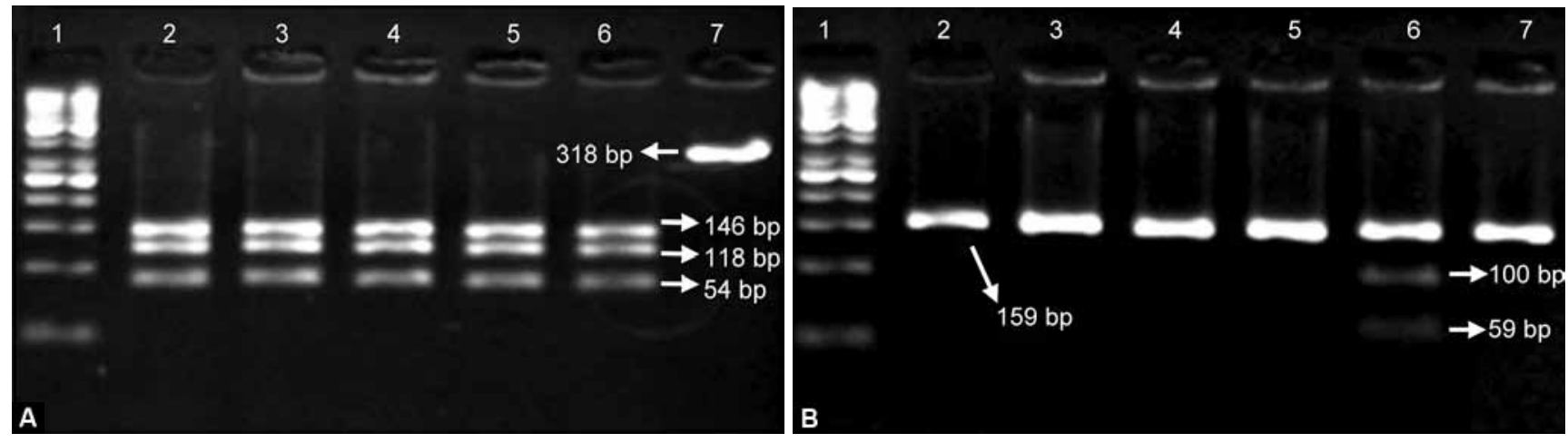

Figs 3A and B: Agarose gel electrophoresis for the analysis of FGFR2 variants. (A) FGFR2 Ser252Trp variant. Lane 1-50 bp molecular weight DNA marker; Lanes 2-5: Wild-type homozygous individuals; Lane 6: A wild-type homozygous amniotic sample (our case); Lane 7: Undigested amplicon, (B) FGFR2 Pro253Arg variant. Lane 1-50 bp molecular weight DNA marker; Lanes 2-5: Wild-type homozygous individuals; Lane 6: A heterozygous amniotic sample, displaying three DNA bands at 159, 100 and 59 bp (our case); Lane 7: Undigested amplicon

Deformities of the skull differ according to the suture involved. Simple craniosynostosis leads to scaphocephaly or dolichocephaly. Premature coronal and metopic suture closure leads to brachycephaly or trigonocephaly. Plagiocephaly appears following the premature ossification of a single coronal or lambdoid suture. The combined ossification of different sutures results in oxycephaly. ${ }^{4}$

Judging by the association of other extracranial anomalies, craniosynostosis is categorized as syndromic (15\%) or isolated $(85 \%){ }^{3}$ Most often, syndromic craniosynostosis 


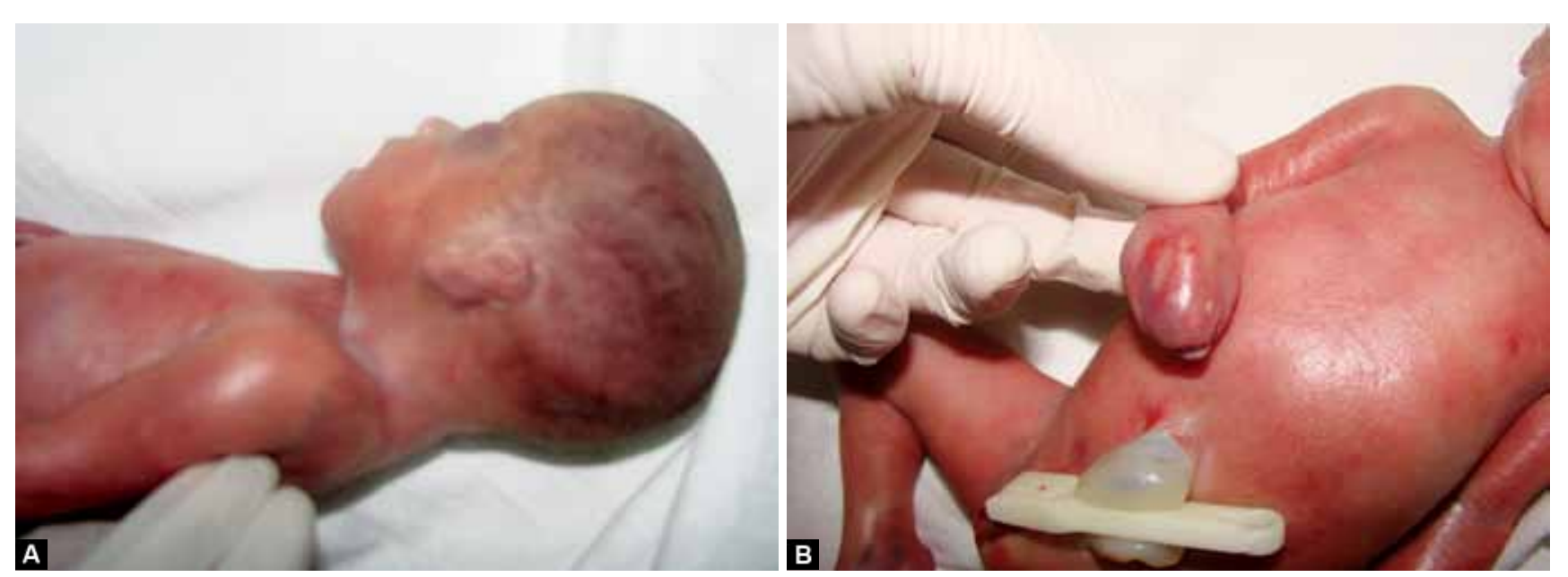

Figs 4A and B: (A) Mediofacial hypoplasia and (B) syndactyly

may be associated with abnormalities of the digits, as in Apert, Crouzon, Pfeiffer and Jackson-Weiss syndromes.

Isolated craniosynostosis is the result of developmental disorders due to strokes, external scalp compression (e.g. amniotic bands) or the action of teratogens (e.g. hydantoin, sodium valproate). ${ }^{5,6}$ Craniosynostosis variants were also described as a component of other syndromes, such as Meckel-Gruber, Williams, osteochondrodysplasia and other genetic autosomal recessive syndromes.

Prenatal diagnosis of craniosynostosis is difficult. Most cases occurring de novo are not diagnosed at routinely performed ultrasound examinations, even by the most experienced of examiners. ${ }^{7}$ Most of the cases diagnosed in intrauterine life were detected during the third trimester of pregnancy. 8,9

Three-dimensional techniques allowed visualization of the normal ossification of the frontal bone. Volumes acquired in the maximum transparent mode, with the selection of acquisition angles as close to $90^{\circ}$ as possible, allow for the calculation of volumes of any of the cranial sutures or fontanelles. ${ }^{10}$ Some studies have focused on the metopic suture, both for its diagnostic value and relatively easy approach. ${ }^{10}$

In Apert syndrome, there is premature ossification of the coronal suture that results in a $\mathrm{Y}$ or $\mathrm{U}$ aspect of the metopic suture. ${ }^{9}$ With $3 \mathrm{D}$ technique an $\mathrm{U}$ image in our case was visualized. These ossification disorders are associated with the presence of a facial dysmorphism (flattened face, bulging fontanelles, saddle-shaped nose).

Moreover, 3D ultrasound volumetric reconstruction leads to a better understanding of the problem and parental assumption of the fetal prognosis. ${ }^{11}$

To our knowledge, this case is among the few diagnosed early (at 22 weeks of gestation) and the first in Romania to have had a prenatal genetic confirmation.

Over $98 \%$ of cases of Apert syndrome have been associated with Ser252Trp (S252W) and Pro253Arg (P253R) variants of the FGFR2 gene. In our case, the Pro253Arg (P253R) variant was identified.

Considering the sporadic occurrence, the autosomal dominant inheritance pattern of the mutation, and the absence of similar heredocolateral antecedents, the syndrome was most likely caused by a de novo mutation in our case.

The incidence of the syndrome rises sharply with the age of the father. ${ }^{5,12}$ In our case, the age of the father (41 years old) could be a risk factor.

In contrast, Glaser et al reported a significantly greater mutation rate in a group of young men who had children and suggested that there are many other relevant environmental factors in addition to parental age. ${ }^{13}$

In our case, the presence of polyhydramnios and symmetric syndactyly were ultrasound elements based on which the suspicion of a malformation syndrome was raised. Hydramnios associated with Apert syndrome has previously been reported in two other cases: a fetus with respiratory airway obstruction ${ }^{14}$ and a fetus with cheilopalatoschisis. ${ }^{15}$ In our case, hydramnios cannot be directly associated with the malformative fetal pathology, but its occurrence in the framework of the maternal pathology (diabetes mellitus) cannot be excluded. Eventually, the association of hydramnios allowed for a better evaluation of fetal surfaces, thus facilitating diagnosis.

Three types of syndactyly are described in the literature (Upton classification). Hand deformities are divided into 3 types, corresponding to increasing severity. Type 1 consists of a complex (osseous and soft-tissue) syndactyly of digits 2 through 5, with the thumb free, which is described as the spade hand. A type 2 deformity involves a complex syndactyly of digits 2 through 5 , with an associated simple syndactyly of the thumb. This has been described as the spoon or mitten hand. A type 3 deformity consists of complex syndactyly of digits 1 through 5, with complex syndactyly of the thumb; it has been described as the rosebud hand. ${ }^{16}$ In our case, there was a type 2 syndactyly. 
The prognosis for this couple is favorable; the probability of recurrence of a genetic event during gametogenesis is improbable. However, a subsequent pregnancy will require close surveillance of the fetal morphology. Additionally, we could consider chorionic villus sampling or amniocentesis to identify FGFR2 mutations.

\section{CONCLUSION}

Early diagnosis of Apert syndrome is possible in the second trimester of pregnancy corroborating 3D acquisitions with molecular genetics findings.

\section{REFERENCES}

1. Kiliç Ü, Baykara Y, Semercü CN, Ergün H, Şatiroğlu Tufan NL. Apert Syndrome. Turk J Med Sci 2004;34:405-408.

2. Slaney SF, Oldridge M, Hurst JA, Moriss-Kay GM, Hall CM, Poole MD, Wilkie AO. Differential effects of FGFR2 mutations on syndactyly and cleft palate in Apert syndrome. Am J Hum Genet 1996;58:923-932.

3. Delahaye S, Bernard JP, Rénier D, Ville Y. Prenatal ultrasound diagnosis of fetal craniosynostosis. Ultrasound Obstet Gynecol 2003;21:347-353.

4. Sadler TW, Sadler T. Langman's Medical Embryology, 12th ed. Lippincott Williams and Wilkins: Philadelphia, 2011.

5. Chabrolle JP, Bensouda B, Bruel H, Simon A, Poinsot J, Ickowicz V, Degre S. Metopic craniosynostosis, probable effect of intrauterine exposure to maternal valproate treatment. Arch Pediatr 2001;8:1333-1336.

6. Lajeunie E, Barcik U, Thorne JA, Ghouzzi VE, Bourgeois M, Renier D. Craniosynostosis and fetal exposure to sodium valproate. J Neurosurg 2001;95:778-782.
7. Quintero-Rivera F, Robson CD, Reiss RE, Levine D, Benson C, Mulliken JB, Kimonis VE. Apert syndrome: what prenatal radiographic findings should prompt its consideration? Prenat Diagn 2006;26:966-972.

8. David AL, Turnbull C, Scott R, Freeman J, Bilardo CM, van Maarle M, Chitty LS. Diagnosis of Apert syndrome in the second-trimester using 2D and 3D ultrasound. Prenat Diagn 2007;27:629-632.

9. Chaoui R, Levaillant JM, Benoit B, Faro C, Wegrzyn P, Nicolaides KH. Three-dimensional sonographic description of abnormal metopic suture in second- and third-trimester fetuses. Ultrasound Obstet Gynecol 2005;26:761-764.

10. Faro C, Benoit B, Wegrzyn P, Chaoui R, Nicolaides KH. Threedimensional sonographic description of the fetal frontal bones and metopic suture. Ultrasound Obstet Gynecol 2005;26: 618-621.

11. Moes JA, Boyle JG, Flanagan JD, Mroch AR, Stein QP. Threedimensional ultrasound to detect Apert syndrome and improve patient understanding. SD Med 2011;64:125-127.

12. Ciurea AV, Toader C. Genetics of craniosynostosis: review of the literature. J Med Life 2009;2:5-17.

13. Glaser RL, Broman KW, Schulman RL, Eskenazi B, Wyrobek AJ, Jabs EW. The paternal-age effect in Apert syndrome is due, in part, to the increased frequency of mutations in sperm. Am J Hum Genet 2003;73:939-947.

14. Chen CP, Lin SP, Su YN, Chen CY, Tsai FJ, Liu YP, Chern SR, Wu PC, Chen HEC, Wang W. Apert syndrome associated with upper airway obstruction and gastroesophageal reflux inducing polyhydramnios in the third trimester. Taiwan J Obstet Gynecol 2010;49:231-234.

15. Filkins K, Russo JF, Boehmer S, Camous M, Przylepa KA, Jiang W, Jabs EW. Prenatal ultrasonographic and molecular diagnosis of Apert syndrome. Prenat Diagn 1997;17:1081-1084.

16. Harvey I, Brown S, Ayres O, Proudman T. The Apert handangiographic planning of a single-stage, 5-digit release for all classes of deformity. J Hand Surg Am 2012;37:152-158. 